\title{
Evaluation of prognostic factors of decompressive craniectomy in the treatment of severe traumatic brain injury
}

\author{
Avaliação dos fatores prognósticos da craniectomia descompressiva no \\ tratamento do traumatismo cranioencefálico grave
}

\author{
Nelson Saade ${ }^{1}$; José Carlos Esteves Veiga, TCBC-SP1; Luiz Fernando Cannoni1 ; Luciano Haddad ${ }^{1}$; João luiz Vitorino Araújo¹.
}

\author{
A B $\quad S \quad T$ R A C C T
}

\begin{abstract}
Objective: to determine predictive factors for prognosis of decompressive craniectomy in patients with severe traumatic brain injury (TBI), describing epidemiological findings and the major complications of this procedure. Methods: we conducted a retrospective study based on analysis of clinical and neurological outcome, using the extended Glasgow outcome in 56 consecutive patients diagnosed with severe TBI scale treated in the emergency department from February 2004 to July 2012. The variables assessed were age, mechanism of injury, presence of pupillary changes, Glasgow coma scale (GCS) score on admission, CT scan findings (volume, type and association of intracranial lesions, deviation from the midline structures and classification in the scale of Marshall and Rotterdam). Results: we observed that $96.4 \%$ of patients underwent unilateral decompressive craniectomy (DC) with expansion duraplasty, and the remainder to bilateral DC, 53.6\% of cases being on the right $42.9 \%$ on the left, and $3.6 \%$ bilaterally, with predominance of the fourth decade of life and males (83.9\%). Complications were described as transcalvarial herniation (17.9\%), increased volume of brain contusions (16.1\%) higroma (16.1\%), hydrocephalus $(10.7 \%)$, swelling of the contralateral lesions (5.3\%) and CSF leak (3.6\%). Conclusion: among the factors studied, only the presence of mydriasis with absence of pupillary reflex, scoring 4 and 5 in the Glasgow Coma Scale, association of intracranial lesions and diversion of midline structures (DML) exceeding $15 \mathrm{~mm}$ correlated statistically as predictors of poor prognosis.
\end{abstract}

Key words: Decompressive craniectomy. Intracranial hypertension/etiology. Intracranial hypertension/surgery. Brainedema/surgery. Brain injuries/complications.

\section{INTRODUCTION}

T he technique of decompressive craniectomy (DC) has been known for over a century and its usefulness was questioned throughout history. It was first described by Kocher in 1901 1, and since 1968 several studies ${ }^{2-4}$ have shown that decompressive craniectomy is a viable strategy for the treatment of refractory intracranial hypertension in patients with severe traumatic brain injury, although the results regarding recovery discourage its use ${ }^{5}$. In 1971, after the introduction of Computerized Tomography, Ransohoff et al. demonstrated $40 \%$ survival, with $27 \%$ of patients returning to their activities despite the technical and aesthetic problems of the method ${ }^{6}$. Its use reappeared after the work of Guerra et al, in $1998^{7}$, being used also in cerebrovascular diseases ${ }^{8,9}$.

A decompressive craniectomy involves removing a large bone flap, associated with durotomy and expansion duraplasty, preferably using an autologous aponeurotic galea graft, promoting reduction of intracranial pressure in an immediate and lasting way ${ }^{10,11}$, accommodating the swollen brain and preventing the development of intracranial brain hernias, being considered a rescue measure in cases of acute intracranial hypertension. The bone flap can be temporarily housed in the abdominal subcutaneous tissue, kept in a bone bank or be prepared for subsequent cranioplasty with heterologous materials.

In the last decade there has been renewed interest in the use of decompressive craniectomies, but questions remain about patient selection, surgical time and technique, time interval until completion of cranioplasty, methodrelated complications, prognosis and quality of life of patients who are subjected to this treatment ${ }^{12}$. The European Brain Injury Consortium (EBIC) and the guidelines of the Brain Trauma Foundation ${ }^{13}$ refer to decompressive craniectomy as a second level measure of for the treatment of refractory intracranial hypertension. Because it is considered as a rescue procedure, it is of paramount importance to study its predictors of prognosis, with the aim to rationalize therapeutic indications.

1. Department of Neurosurgery, Faculty of Medical Sciences, Irmandade da Santa Casa de Misericórdia de São Paulo. 
The goal of this study was to determine the predictive factors for prognosis of decompressive craniectomy in patients with severe traumatic brain injury, describing the epidemiological findings and the major complications associated with the method.

\section{METHODS}

We conducted a retrospective analysis of medical charts 56 consecutive patients seen in the Emergency Room of the Santa Casa de São Paulo in the period from February 2004 to July 2012, undergoing decompressive craniectomy with diagnosed severe brain injury, defined as those with GCS scores between 4 and 9 points, after the initial treatment based on ATLS (Advanced Trauma Life Support) protocol. The evolution was assessed using scale extended Glasgow (GOSE) ${ }^{14}$. The factors assessed were age, mechanism of injury, presence of pupillary changes, GCS score on admission, CT findings (volume, type and association of intracranial lesions, deviation of the midline structures and classification on the scale of Marshall and Rotterdam). Inclusion criteria were age between 18 and 65 years, start of treatment until 72 hours after trauma, evidence of diffuse, severe traumatic brain injury, with or without focal lesion, undergoing unilateral or bilateral decompressive craniectomy.

Exclusion criteria were: extra-axial intracranial hematoma with thickness $>3 \mathrm{~cm}$; cerebral contusion e" $5 \mathrm{~cm}$ on the major axis; prior craniectomy; cardiopulmonary arrest; GCS score 3 with non-fotoreactive, mydriatic pupils; Severe coagulopathy defined as prothrombin activity lower than $50 \%$ and/or platelet count $<70,000$; severe TBI associated with systemic trauma.

As for the admission GCS, we considered the first score described by the neurosurgeon on the medical records of hospitalization. In the case of a patient who arrived intubated and sedated, with no description of the GCS in subsequent assessments, we accepted the scoring described by the pre-hospital staff before intubation. As for the CT data, we classified the preoperative findings in: epidural hematoma (EDH), traumatic subarachnoid hemorrhage (TSAH), intracerebral hematoma (ICH), brain swelling (BS), diffuse axonal injury (DAI). Concerning operative data, we recorded the time interval between admission and surgery.

To reduce the number of variables in the statistical evaluation, we grouped GOSE 1, 2, 3 and 4 as unfavorable outcome, and GOSE 5, 6, 7 and 8 as favorable outcome. We tried to correlate factors for prognosis unfavorable to discharge (GOSE) using the chi-square test of Independence and the Fisher exact test.

The study was approved by the Ethics in Research Committee of the Irmandade da Santa Casa de Misericórdia de São Paulo (opinion number 242543).

\section{RESULTS}

We observed that $96.4 \%$ of patients underwent unilateral CD with expansion duraplasty, $53.6 \%$ of the cases being on the right, $42.9 \%$ on the left, and 3.6\% bilaterally, with predominance of the fourth decade of life and male gender (83.9\%). The predominant mechanism of trauma was motor vehicle-pedestrian collision, with $35.7 \%$ of cases, followed by fall from height, with $19.6 \%$ (Figure 1).

The GCS at admission showed that $44.6 \%$ of patients had 4 points, $7.1 \% 5$ points, $12.5 \% 6$ points, $14.3 \%$ 7 points, $8.9 \% 8$ points and $12.5 \%$ of patients had 9 points. Due to the severity of the clinical condition on admission, $71.4 \%$ of patients underwent definitive surgical treatment in less than six hours.

The evaluation of symmetry and pupillary reactivity at admission showed that $27(48.2 \%)$ had anisocoria, ten patients (17.9\%) with bilateral mydriasis and absent fotoreactivity, and in 19 (33.9\%) the pupils were isochoric and fotoreactive. Regarding the distribution of intracranial lesions, $78.6 \%$ of patients had acute subdural hematoma evidenced by admission CT scan, followed by brain contusion in $28.6 \%$, epidural hematoma in $17.9 \%$, traumatic subarachnoid hemorrhage in $17.9 \%$, traumatic intracerebral hematoma in $8.9 \%$, brain swelling in $7.1 \%$ and diffuse axonal injury in $3.6 \%$ of cases. Associated intracranial lesions were present in $50 \%$ of patients.

The deviation of midline structures (DML) to the septum pellucidum level was above $15 \mathrm{~mm}$ in $39.3 \%$ of patients. The classification of Marshall and Rotterdam showed $69.6 \%$ patients with score 4 , but there was only a trend to an unfavorable prognosis with higher scores when using the Marshall scale $(p=0.06)$.

Regarding the final outcome after six months, there was a high mortality, recorded in $58.9 \%$ of cases. The unfavorable prognosis, characterized by scores 1-4, occurred in $78.5 \%$ of cases, and those considered favorable

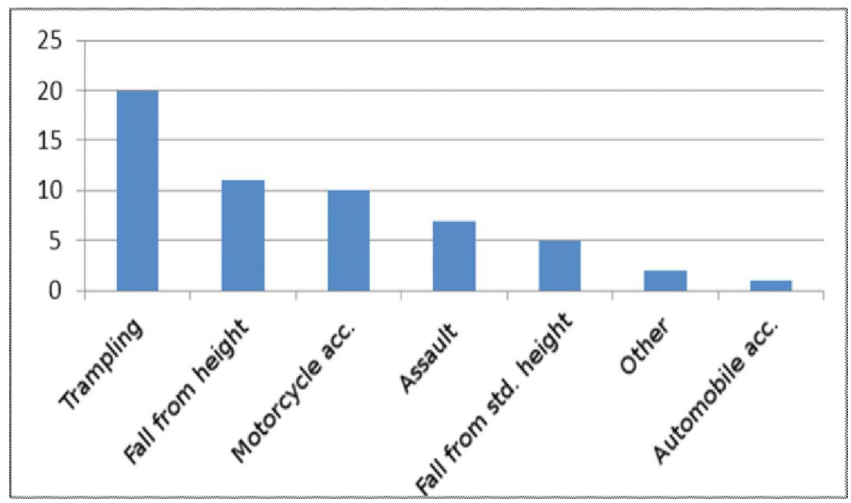

Figure 1 - Frequency distribution of the main mechanisms of trauma. 
prognosis, with scores $5-8$, were observed in $21.5 \%$. Complications of decompressive craniectomy for treatment of traumatic intracranial hypertension are presented in Figure 2 . There was no statistical significance between age and prognosis.

Taking into account only the final outcome as death, there was statistical significance after analysis with the Fisher exact test (0.02) and the chi-square test (0.01) when comparing the group with score $d^{\prime \prime} 5$ with the group with score $>5$ at admission (Table 1).

The distribution related to the estimated time between hospital admission and definitive treatment showed a predominance of unfavorable prognosis in cases where there was an early institution of definitive treatment because, in reality, these cases correspond to those with low GCS at admission (Table 2).

When evaluating the correlation between the pupil changes and prognosis, there was significance only in the presence of mydriasis and absent pupillary reflex, and, in all cases, the score was equal to one, corresponding to death $(p<0,01)$. There was statistical significance $(p=0.05)$ between the presence of multiple intracranial lesions and prognosis evaluated by the GOSE (Table 3).

There was no correlation between the prognosis and the type of focal intracranial lesion evidenced by $\mathrm{CT}$ at admission. We observed a statistically significant correlation between the deviation of the midline structures at $\mathrm{CT}$ and prognosis (Table 4). The deviation of the midline structures, when $>15 \mathrm{~mm}$, proved to be a predictor of poor prognosis $(p<0.01)$.

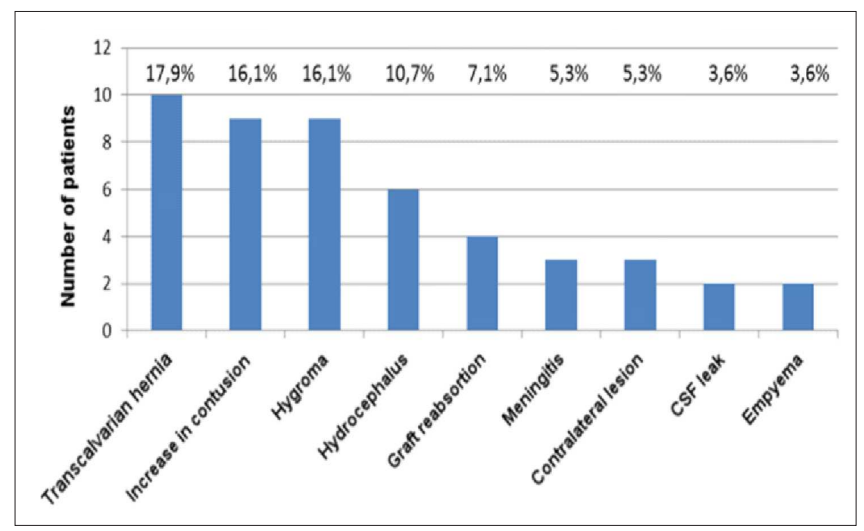

Figure 2 - Distribution frequency of postoperative complications in the 56 patients who underwent decompressive craniectomy.

\section{DISCUSSION}

Decompressive craniectomy (DC) consists of a second level surgical procedure used for the treatment to control refractory intracranial hypertension, of traumatic etiology or not. The benefit of this therapy is associated with improved brain oxygenation, cerebral perfusion pressure and brain compliance due to control of intracranial hypertension $(\mathrm{ICH})^{15}$. Despite $\mathrm{CD}$ has been used for over a century, the effects on clinical outcome are not well known, requiring prospective and randomized studies. There are reports of favorable prognosis in selected patients ${ }^{16}$, but in Brazil few studies have predictive prognostic factors in order to rationalize the indications in cases of severe cranial trau-

Table 1 - Correlation between GCS scores and death.

\begin{tabular}{llcrl}
\hline & Death (\%) & Outcome & Total (\%) \\
\hline Glasgow 4/5 critical & $23(79.3)$ & No death (\%) & \\
Glasgow $>5$ & $10(37 \%)$ & $17(20.7)$ & $29(100)$ \\
Total & $33(58.9)$ & $23(41.1)$ & $27(100)$ \\
\hline
\end{tabular}

Source: SAME ISCMSP

Table 2 - Correlation between time of admission, definitive treatment and prognosis.

\begin{tabular}{|c|c|c|c|}
\hline \multirow[t]{2}{*}{ Time (hours) } & \multicolumn{2}{|c|}{$\begin{array}{l}\text { Prognosis } \\
\end{array}$} & \multirow[t]{2}{*}{ Total (\%) } \\
\hline & Unfavorable (\%) & Favorable (\%) & \\
\hline 1 a 6 & $34 \quad(85)$ & $6 \quad(15)$ & $40 \quad(100)$ \\
\hline 6 а 12 & $7(63.6)$ & $4(36.4)$ & $11(100)$ \\
\hline 12 a 24 & $2(66.7)$ & $1(33.3)$ & $3(100)$ \\
\hline Over 24 & $1 \quad(50)$ & $1 \quad(50)$ & $2(100)$ \\
\hline Total & 44 (78.6) & $12(21.4)$ & $56(100)$ \\
\hline
\end{tabular}

Source: SAME ISCMSP 
Table 3 - Correlation between prognosis and the presence of multiple intracranial lesions.

\begin{tabular}{lcccc}
\hline Intracranial lesion & Unfavorable (\%) & Prognosis & Total (\%) \\
\hline 1 lesion & $19(69.9)$ & $9(32.1)$ & $28(100)$ \\
$>1$ lesion & $25(89.3)$ & $3(10.7)$ & $28(100)$ \\
Total & $44(78.6)$ & $12(21.4)$ & $56(100)$ \\
\hline
\end{tabular}

Source: SAME ISCMSP

Table 4 - Correlation between the prognosis and the deviation of midline structures.

\begin{tabular}{|c|c|c|c|}
\hline \multirow[t]{2}{*}{$\overline{\mathrm{DML}}$} & \multicolumn{2}{|c|}{ Prognosis } & \multirow[t]{2}{*}{ Total (\%) } \\
\hline & Unfavorable (\%) & Favorable (\%) & \\
\hline Up to $15 \mathrm{~mm}$ & $23 \quad(67.6)$ & $11 \quad(32.4)$ & $34(100)$ \\
\hline$>15 \mathrm{~mm}$ & $21 \quad(95.5)$ & $1 \quad(4.5)$ & $22(100)$ \\
\hline Total & $44 \quad(78.6)$ & $12 \quad(21.4)$ & $56(100)$ \\
\hline
\end{tabular}

Source: SAME ISCMSP

ma ${ }^{17}$. In the present study, as for the final outcome after six months, using the Extended Glasgow Outcome Scale (GOSE) ${ }^{14}$, there was high mortality, recorded in $58.9 \%$ of cases. The unfavorable prognosis, characterized by scores $1-4$, occurred in $78.5 \%$ of cases and those deemed as favorable prognosis, with scores $5-8$, were observed in $21.5 \%$. These findings are similar to already demonstrated poor prognosis results ${ }^{15}$.

Since the procedure is a rescue one for the treatment of $\mathrm{ICH}$ refractory to the conventional measures, little is known about the functional results in the longterm. Danish et al. ${ }^{18}$ carried out a systematic literature review to assess the quality of life of patients undergoing $C D$ and conclude that, on average, the mortality rate is $28.2 \%$, but the functional results are not good. Bor-SengShu et al. ${ }^{19}$ showed through a meta-analysis the beneficial effects of $C D$ in relation to reduction of ICH and increased ICP; similarly the results of the multicenter study DECRA demonstrate shorter ICU stay and reduced ICH, but with unfavorable functional outcomes ${ }^{18}$. Another study currently being finalized is the RESCUEicp questioning the analysis of the results of the DECRA, differing from the latter in the limit of the ICP (25 mmHg vs. $20 \mathrm{mmHg}$ ), moment for surgery (any time after injury versus 72 hours after injury), inclusion of cerebral contusions, and longer follow up (two years). The cohort profiles and criteria for inclusion and randomization between the DECRA and the RESCUEicp are therefore very different and thus the results of the DECRA study should not influence the results of RESCUEicp.

Regarding epidemiological data, there was predominance of young people up to the fourth decade of life and males (83.9\%), being consistent with that reported in other series ${ }^{20}$, due to the fact that this population is more exposed to traumatic incidents. TBI affects the young and productive portion of the population, causing enormous medical and socioeconomic repercussions. As for the correlation between age and prognosis evaluated in the sample by the Extended Glasgow Outcome Scale, we used the Student t test and statistical significance was not observed, unlike other studies in the literature that present mortality of $19.2 \%$ in patients under 35 years of age, reaching $80 \%$ in patients older than 65 years ${ }^{21}$. Despite some contradictions, it is reported that children with severe brain injury have better outcomes than adults, even when the use of decompressive craniectomy is assessed ${ }^{16}$. The significant influence of age on the outcome is not explained by the increased frequency of systemic complications or intracerebral hematomas. Most studies indicate that age is a strong independent prognostic factor, with a significant increase in adverse outcomes over 60 years of age.

The mechanism of trauma observed more frequently in $35.7 \%$ of cases was trampling, showing a higher susceptibility to severe traumatic brain injury to pedestrians, especially in large urban centers of developing countries with exponential vehicle fleet growth. The national study of Martins et al., carried out according to the Traumatic Coma Data Bank, highlights the same dominance in relation to the trauma mechanism ${ }^{20}$, while the original analysis of the TCDB points to automobile accidents. Updated data from the Centers for Disease Control and Prevention of the United States put the falls (35.2\%) and motor vehicle accidents (17.3\%) as the main causes. This difference also occurs because the present study only stratified patients with severe TBI. The World Health Organization (WHO) estimates that by 2020 traffic accidents will contribute to the third leading cause of traumatic injuries. 
The distribution observed for the initial GCS score, respecting the inclusion criteria, had $44.6 \%$ of patients with score 4 , confirming the extreme seriousness of cases that underwent decompressive craniectomy. In general, the GCS has an inversely proportional relationship between its score and the prognosis of patients with TBI. Narayan et al. have shown an unfavorable prognosis in $77 \%$ of patients with scores between 3 and $5^{22}$. Potts et al. argue that the GCS has no significant predictive value in patients undergoing $C D$, except those in the specific age group between 35 and 49 years, with statistical significance $(p=0.011)^{21}$. The present study showed unfavorable prognosis in $89.7 \%$ of cases with GCS score 4 and 5, considering only the final outcome as death, having significance when compared with the group with score 6-9.

We observed that due to the severity of disease at admission, $71.4 \%$ of patients underwent surgical treatment for a maximum period of six hours, most severe cases (GCS up to 5) receiving definitive treatment during this period, totaling $57.5 \%$. This explains the predominance of unfavorable prognosis in cases where there was an early institution of definitive treatment $(85.6 \%)$, since these cases correspond to those that scored low on the GCS at admission. Therefore, one should not interpret the cases submitted to delayed treatment had better prognosis.

All cases with bilateral mydriasis an absence of pupillary reflex on admission had an unfavorable prognosis, with only one point in the GOSE, ie, death. There was statistical significance $(p<0.01)$ between this finding and death as the final outcome. These findings are in line with those described by Narayan et al. ${ }^{22}$, with $70 \%$ unfavorable prognosis, therefore, the absence of bilateral fotoreactivity was factor predictive of prognosis in this study, and there being statistical significance when death was used as outcome.

As for the presence of intracranial lesions, half of the sample had associated injuries, and there was clear predominance $(78.6 \%)$ of acute subdural hematoma, followed by brain contusion in $28.6 \%$ of cases. After applying the chi-square and Fisher exact tests, no correlation between the prognosis and the type of focal intracranial lesions was observed, but there has been a statistically significant difference with regards to the presence of associated injuries, $89.3 \%$ progressing to unfavorable prognosis when compared with $67.9 \%$ of those who had a single lesion. Literature data regarding these findings indicate mortality of $85 \%$ for acute subdural hematoma associated with unilateral contusion and $17 \%$ in the absence of these ${ }^{23}$. Studies with level I evidence show prognostic predictive value of $67 \%$ for unfavorable outcome in the presence of combination of intra and extra-axial brain injuries ${ }^{22}$.

Upon tomographic analysis, the sample had $39.3 \%$ of cases with more than $15 \mathrm{~mm}$ deviation from the midline. We observed a statistically significant correlation between the deviation of the midline structures observed in the tomography and prognosis. The deviation of more than $15 \mathrm{~mm}$ proved to be a predictor of poor prognosis $(p=0.01)$. In these cases there was an unfavorable prognosis in $95.5 \%$, against $67.6 \%$ of those with $\mathrm{DML}<15 \mathrm{~mm}$. Some studies report that the deviation of the midline structures is considered a predictor of prognosis ${ }^{24}$. Traumatic Coma Data Bank data show that DML e" 3mm was evidenced in $34 \%$ of patients, with $70 \%$ mortality when the DML is $15 \mathrm{~mm}$ or beyond ${ }^{25,26}$. In both scales of Marshall and Rotterdam, used for the classification of CT findings in our study, there was a predominance $(69.6 \%)$ of the results with four points. The analysis performed using Student $t$ and Fisher exact tests demonstrated a tendency to poor prognosis in patients with higher scores on the Marshall scale, whose findings were $66.7 \%$ with score 3, 76.9\% with score 4 and $85.7 \%$ with score 5 , but without statistical significance $(p>0.05)$, perhaps due to sample size. Similarly, it was not possible to establish any correlation between the prognosis and the Rotterdam tomography scale in patients undergoing DC. Huang et al. ${ }^{27}$ concluded that the Rotterdam scale has a great propensity to be an independent predictor of poor prognosis in patients with TBI undergoing CD. The relationship between score and prognosis was quantified and the score was significantly associated with mortality $(p<0.001)$ and poor prognosis ( $p$ $<0.001)$.

The analysis of the series demonstrated complications in $46.4 \%$ of cases, accounting for early and late presentation. The most frequent was transcalvarian hernia, in $17.9 \%$ of cases, followed by increased volume of cerebral contusions, hygroma, hydrocephalus, increased volume of contralateral lesions and cerebrospinal fluid fistula (Figure 2). Compared with literature data, we have that Faleiro et al. described $34.8 \%$ of patients with complications related to $C D$ in patients with $T B I$, distributed as subdural collection in $11.2 \%$, hydrocephalus in $7.9 \%$ and infection in $15.7 \%{ }^{17}$. In this study the infectious complications, evidenced in $8.9 \%$ of cases, were meningitis (5.3\%) and empyema (3.6\%). In four cases (7.1\%), we observed delayed resorption of the bone flap previously stored in the subcutaneous tissue of the abdomen.

The transcalvarian hernia observed in $17.9 \%$ of cases is described in the literature in up to $26 \%$ of cases, caused by the induced edema and increased capillary perfusion and hydrostatic gradient after decompression 12. Potential adverse effects include compression of cortical veins. Therefore, more extensive craniectomies reduce the chance of venous ischemia. Changes of cerebrospinal fluid circulation after decompressive craniectomy are among the most frequent complications reported in the literature, causing hydrocephalus and subdural collections. After CD, there is experimentally reduced resistance in the circulation of cerebrospinal fluid in half, while the brain complacency increases. Kaen et al. described hydrocephalus in $27.4 \%$ of cases, with statistical significance $(p=0.0001)$ when 
correlating cases with inter-hemispheric hygroma and hydrocephalus ${ }^{28}$. Choi et al. reported that the incidence of post-traumatic hydrocephalus increases from $2.4 \%$ to $23.6 \%$ when treatment includes $C D$, being primarily related to more extensive craniectomies and reoperations ${ }^{29}$. Kaen et al. showed subdural hygromas in the first week after $C D$, with gradual increase up to four weeks and spontaneous resolution in 17 weeks $^{28}$. Rebound and hydrodynamic phases are also described, not observed in the present study.

Infectious complications are described in the literature in $2-6 \%$ of cases submitted to $C D^{30}$ and usually occur late, manifesting as meningitis and empyema. The increase in infection rates may be related to dehiscence, cerebrospinal fluid leak and early cranioplasty. In the present study we used autologous bone in cranioplasty, stored in a bone bank whenever possible. In this research, we found lower complication rates when the period of realization of cranioplasty occurs within at three months when compared with those carried out after six months.

In conclusion, among the factors studied, only the presence of mydriasis with absence of pupillary reflex, GCS scores 4 and 5 , association of intracranial lesions and $\mathrm{DM}>15 \mathrm{~mm}$ correlated statistically as predictors of poor prognosis.

Regarding the epidemiological data, $96.4 \%$ of patients underwent unilateral CD with expansion duraplasty, $53.6 \%$ of the cases being on the right, $42.9 \%$ on the left, and $3.6 \%$ bilaterally, predominantly in young people, until the fourth decade of life, and males (83.9\%). The most common mechanism of trauma was trampling, followed by fall from height. The main complications related to the technique were transcalvarian herniation, followed by increased volume of cerebral contusions, hygroma, hydrocephalus, increased volume of contralateral lesions (5.3\%) and CSF leak.

\section{R E S U M O}

Objetivo: determinar fatores preditivos de prognóstico da craniectomia descompressiva, em pacientes com traumatismo cranioencefálico grave (TCE) descrevendo achados epidemiológicos e as principais complicações do método. Métodos: estudo retrospectivo mediante análise da evolução clínica e neurológica, utilizando a escala estendida de resultados de Glasgow em 56 pacientes consecutivos atendidos no Serviço de Emergência no período de fevereiro de 2004 a julho de 2012, diagnosticados com TCE grave. Os fatores avaliados foram a idade, o mecanismo de trauma, a presença de alterações pupilares, a pontuação na escala de coma de Glasgow (ECG) à admissão, achado tomográfico (volume, tipo e associação de lesões intracranianas, desvio das estruturas da linha média e classificação na escala de Marshall e Rotterdam). Resultados: observou-se que 96,4\% dos casos foram submetidos à craniectomia descompressiva (CD) unilateral com duroplastia de expansão e o restante, CD bilateral, sendo 53,6\% dos casos à direita, 42,9\% à esquerda e 3,6\% bilateralmente, com predomínio até a quarta década de vida e sexo masculino (83,9\%). As complicações descritas foram a herniação transcalvárica (17,9\%), aumento do volume de contusões cerebrais (16,1\%), higroma $(16,1 \%)$, hidrocefalia (10,7\%), aumento de volume de lesões contralaterais (5,3\%) e fístula liquórica (3,6\%). Conclusão: entre os fatores estudados, apenas a presença de midríase com ausência de reflexo fotomotor, pontuação 4 e 5 na escala de coma de Glasgow, associação de lesões intracranianas e desvio de estruturas da linha mediana (DLM) superior a 15mm correlacionaram-se estatisticamente como fatores preditivos de prognóstico desfavorável.

Descritores: Craniectomia descompressiva. Hipertensão intracraniana/etiologia. Hipertensão intracraniana/cirurgia. Edema encefálico/cirurgia. Traumatismos encefálicos/complicações.

\section{REFERENCES}

1. Kocher T. Die therapie des hirndruckes. In: Hölder A, editor Hirnerschütterung, Hirndruck und chirurgische Eingriffe bei Hirnkrankheiten. Vienna: A. Hölder; 1901. p. 262-6.

2. Kerr FW. Radical decompression and dural grafting in severe cerebral edema. Mayo Clin Proc. 1968;43(12):852-64.

3. Kjellberg RN, Prieto A Jr. Bifrontal decompressive craniotomy for massive cerebral edema. J Neurosurg. 1971;34(4):488-93.

4. Venes JL, Collins WF. Bifrontal decompressive craniectomy in the management of head trauma. J Neurosurg. 1975;42(4):429-33.

5. Clark K, Nash TM, Hutchison GC. The failure of circumferential craniotomy in acute traumatic cerebral swelling. J Neurosurg.1968;29(4):367-71.

6. Ransohoff J, Benjamin MV, Gage L Jr, Epstein F. Hemicraniectomy in the management of acute subdural hematoma. J Neurosurg. 1971;34(1):70-6.

7. Guerra WK, Gaab MR, Dietz H, Mueller JU, Piek J, Fritsch MJ. Surgical decompression for traumatic brain swelling: indications and results. J Neurosurg. 1999;90(2):187-96.
8. Schirmer CM, Hoit DA, Malek AM. Decompressive hemicraniectomy for the treatment of intractable intracranial hypertension after aneurysmal subarachnoid hemorrhage. Stroke. 2007;38(3):98792.

9. Rahme R, Zuccarello M, Kleindorfer D, Adeoye OM, Ringer AJ. Decompressive hemicraniectomy for malignant middle cerebral artery territory infarction: is life worth living? J Neurosurg. 2012;117(4):749-54.

10. Hutchinson P, Timofeev I, Kirkpatrick P. Surgery for brain edema Neurosurg Focus. 2007;22(5):E14.

11. Cooper DJ, Rosenfeld JV, Murray L, Arabi YM, Davies AR, D'Urso $P$, et al. Decompressive craniectomy in diffuse traumatic brain injury. N Engl J Med. 2011;364(16):1493-502.

12. Stiver SI. Complications of decompressive craniectomy for traumatic brain injury. Neurosurg Focus. 2009;26(6):E7.

13. Brain Trauma Foundation; American Association of Neurological Surgeons; Congress of Neurological Surgeons. Guidelines for the management of severe traumatic brain injury. J Neurotrauma. 2007;24 Suppl 1:S1-106. Erratum in: J Neurotrauma. 2008;25(3):276-8. 
14. Teasdale GM, Pettigrew LE, Wilson JT, Murray G, Jennett B. Analyzing outcome of treatment of severe head injury: a review and update on advancing the use of the Glasgow Outcome Scale. J Neurotrauma. 1998;15(8):587-97.

15. Chesnut RM, Ghajar J, Maas AIR, Marion DW, Servadei F, Teasdale GM, et al. Part 2: Early indicators of prognosis in severe traumatic brain injury. J Neurotrauma. 2000;17(6-7):557-627.

16. Sahuquillo J, Arikan F. Decompressive craniectomy for the treatment of refractory high intracranial pressure in traumatic brain injury. Cochrane Database Syst Rev. 2006;25(1):CD003983.

17. Faleiro RM, Faleiro LC, Caetano E, Gomide I, Pita C, Coelho G, et al. Decompressive craniotomy: prognostic factors and complications in 89 patients. Arq Neuropsiquiatr. 2008;66(2B):369-73.

18. Danish SF, Barone D, Lega BC, Stein SC. Quality of life after hemicraniectomy for traumatic brain injury in adults. A review of the literature. Neurosurg Focus. 2009;26(6):E2.

19. Bor-Seng-Shu E, Figueiredo EG, Amorim RL, Teixeira MJ, Valbuza JS, de Oliveira MM, et al. Decompressive craniectomy: a metaanalysis of influences on intracranial pressure and cerebral perfusion pressure in the treatment of traumatic brain injury. J Neurosurg. 2012;117(3):589-96.

20. Martins ET, Silva TS, Coutinho M. Estudo de 596 casos consecutivos de traumatismo craniano grave em Florianópolis - 1994-2001. Rev Bras Ter Intensiva. 2003;15(1):15-8.

21. Potts MB, Chi JH, Meeker M, Holland MC, Claude HJ 3rd, Manley GT. Predictive values of age and the Glasgow Coma Scale in traumatic brain injury patients treated with decompressive craniectomy. Acta Neurochir Suppl. 2008;102:109-12.

22. Narayan RK, Greenberg RP, Miller JD, Enas GG, Choi SC, Kishore $\mathrm{PR}$, et al. Improved confidence of outcome prediction in severe head injury. A comparative analysis of the clinical examination, multimodality evoked potentials, CT scanning, and intracranial pressure. J Neurosurg. 1981;54(6):751-62.

23. Kotwica Z, Brzeziñski J. Acute subdural haematoma in adults: an analysis of outcome in comatose patients. Acta Neurochir. 1993;121(3-4):95-9.
24. Fearnside MR, Cook RJ, McDougall P, McNeil RJ. The Westmead Head Injury Project outcome in severe head injury. A comparative analysis of pre-hospital, clinical and CT variables. Br J Neurosurg. 1993;7(3):267-79.

25. Zumkeller M, Behrmann R, Heissler HE, Dietz H. Computed tomographic criteria and survival rate for patients with acute subdural hematoma. Neurosurgery. 1996;39(4):708-12; discussion 712-3.

26. Eisenberg HM, Gary HE Jr, Aldrich EF, Saydjari C, Turner B, Foulkes $M A$, et al. Initial CT findings in 753 patients with severe head injury. A report from the NIH Traumatic Coma Data Bank. J Neurosurg. 1990;73(5):688-98.

27. Huang YH, Deng YH, Lee TC, Chen WF. Rotterdam computed tomography score as a prognosticator in head-injured patients undergoing decompressive craniectomy. Neurosurgery. 2012;71(1):80-5

28. Kaen A, Jimenez-Rolda L, Alday R, Gomez PA, Lagares A, Alén JF, et al. Interhemispheric hygroma after decompressive craniectomy: does it predict posttraumatic hydrocephalus? J Neurosurg. 2010;113(6):1287-93

29. Choi I, Park HK, Chang JC, Cho SJ, Choi SK, Byun BJ. Clinical factors for the development of posttraumatic hydrocephalus after decompressive craniectomy. J Korean Neurosurg Soc. 2008;43(5):227-31.

30. Yang XF, Wen L, Shen F, Li G, Lou R, Liu WG, et al. Surgical complications secondary to decompressive craniectomy in patients with a head injury: a series of 108 consecutive cases. Acta Neurochir. 2008;150(12):1241-7; discussion 1248.

Received on 21/08/2013

Accepted for publication 22/10/2013

Conflict of interest: none.

Source of funding: none.

Mailing address:

Nelson Saade

E-mail: nsaade@msn.com 